\title{
Teaching optical dimensional metrology of surfaces and international standards
}

\section{Manuel F. Costa}

Manuel F. M. Costa, "Teaching optical dimensional metrology of surfaces and international standards," Proc. SPIE 9289, 12th Education and Training in Optics and Photonics Conference, 92890F (17 July 2014); doi: 10.1117/12.2070749

SPIE Event: 12th Education and Training in Optics and Photonics Conference, 2013, Porto, Portugal 


\title{
TEACHING OPTICAL DIMENSIONAL METROLOGY OF SURFACES AND INTERNATIONAL STANDARDS
}

\author{
Manuel F. M. Costa \\ Departamento de Física da Universidade do Minho (Portugal) \\ mfcosta@fisica.uminho.pt
}

Dimensional metrology is a demanding subject that requires an in-depth knowledge not only of the characteristics of the object of the measurement and the method and system to be used to perform the measurement but also of the standards to followed and strictly respected. This is especially true for surface metrology. The definition of surface, particularly when using optical methods in the measuring process, is a first problem to be understood. From this definition discussion, in our pedagogical approach, we move to the study of the characteristics of light and light/matter/surface interaction. Surface characterization parameters and the main ISO standards are studied. Particular attention is given within the study of the sensing/measuring processes to the definition of uncertainty of a measurement. ISO' Guide of Expression of Uncertainty of a Measurement, GUM, is studied (as well as the VIM). A review of the main optical surface inspection system is made. We believe on the importance of an active student centred learning and on the resource to hands-on experimental practice and therefore all this teaching approach evolves from practical examples and actual experiments and observations.

Key words: ISO standards, optical metrology. 